\title{
Effects of Intravenous Administration of Tranexamic Acid in Reducing Blood Loss during and After Caesarean Section
}

\section{Anita Kant ${ }^{1 *}$, Usha Priyambada Gupta ${ }^{2}$, Amrita Razdan Kaul ${ }^{3}$ and Shephali ${ }^{4}$}

${ }^{1}$ Chairman, Department of Obstetrics and Gynaecology, Asian institute of Medical Sciences, Faridabad, Haryana, India

${ }^{2}$ Senior Consultant, Department of Obstetrics and Gynaecology, Asian institute of Medical Sciences, Faridabad, Haryana, India

${ }^{3}$ Consultant, Department of Obstetrics and Gynaecology, Asian Institute of Medical

Sciences, Faridabad, Haryana, India

${ }^{4}$ DNB Resident, Final Year, Department of Obstetrics and Gynaecology, Asian institute of Medical Sciences, Faridabad, Haryana, India

*Corresponding Author: Anita Kant, Chairman, Department of Obstetrics and Gynaecology, Asian institute of Medical Sciences, Faridabad, Haryana, India.
Received: June 17, 2021

Published: July 09, 2021

(C) All rights are reserved by Anita Kant, et al.

\section{Abstract}

Objective: To study the safety and efficacy of Tranexamic acid (TXA) in reducing blood loss during and after the caesarean section.

Methodology: This is a randomized, case controlled, prospective open label trial conducted on ninety term pregnant females undergoing caesarean in our hospital for evaluating the blood loss with or without the use of TXA. Patients were randomly assigned to either cases (Receiving injection TXA) or controls (Not receiving TXA).

Results: Mean of total blood loss among cases was $267.27 \pm 115.77 \mathrm{ml}$, while it was $428.13 \pm 98.24 \mathrm{ml}$ in controls ( $\mathrm{p}$ value $<0.001$ ). Its use was not associated with any side effect or complications like Thrombosis. Overall, the study supports the evidence of beneficial effects of TXA in significantly reducing blood loss during and after CS and hence reducing the need for blood transfusion.

Conclusion: TXA is effective in reducing blood loss during and after caesarean section.

Keywords: Bleeding; Caesarean Section; Postpartum; Tranexamic Acid

\section{Abbreviation}

TXA: Tranexamic Acid; CS: Caesarean Section; PPH: Postpartum Hemorrhage

\section{Introduction}

The rate of caesarean section (CS) has increased in both developed and developing countries in recent decades [1]. The World
Health Organization (WHO) estimated around 5\% to 15\% rate of caesarean section in any population [2]. In India, CS rate was approximately $17.2 \%$ in 2015 which was twice that from the year 2005 [3]. Delivery by CS is associated with more complications than vaginal delivery. One of the most common complications is postpartum hemorrhage (PPH), which is one of the leading cause of preventable maternal mortality worldwide [4]. 
PPH is defined as blood loss of more than $1000 \mathrm{ml}$ following caesarean delivery.

A popular approach is to minimize peri-operative bleeding through the prophylactic use of the antifibrinolytic agents aprotinin, tranexamic acid (TXA) by intravenous administration for many years to reduce hemorrhage during and after many surgical procedures like coronary artery bypass, scoliosis surgery, oral surgery, total hip or knee arthroplasty and urinary tract surgery [5]. Tranexamic acid is a synthetic derivative of the amino acid lysine that exert its antifibrinolytic effect through the reversible blockade of the lysine binding sites on plasminogen molecules.

The antifibrinolytic effect of tranexamic acid in the third stage of labour could make it a safe and effective alternative or adjunct to other regimens currently used in the third stage of labour for prevention of $\mathrm{PPH}$.

Its Effectiveness in reducing PPH is being evaluated in the WOMAN trial (World Maternal Antifibrinolytic Trial -London School of Hygiene and Tropical Medicine). The primary outcome of the trial, death from haemorrhage, was reduced by approximately one third (1.5\% treatment group; $1.9 \%$ placebo; $\mathrm{RR}=0.81 ; 95 \% \mathrm{CI}$, 0.65-1.00; $\mathrm{P}=0.045$ ) [12].

\section{Material and Methods}

This randomized, case controlled, prospective open label study was conducted at Department of Obstetrics and gynecology at Asian institute of medical sciences, Faridabad from September 2019 till August 2020. Term pregnant females who delivered by cesarean section in our hospital during the study were included in the study for evaluating their blood loss with or without the use of tranexamic acid. Ninety consecutive patients undergoing primary CS in our department were randomly assigned to either group $\mathrm{A}$ (cases): patients given $1 \mathrm{gm} / 10 \mathrm{ml}$ TXA diluted with $20 \mathrm{ml}$ of $5 \%$ glucose $(n=45)$ or group $B$ (controls): patient not given TXA $(n=$ 45).

\section{Exclusion criteria}

- Severe medical and surgical complications including the heart, liver and kidney, brain disease and blood disorders (anemia requiring blood transfusion).

- Allergy to tranexamic acid.

- History of thromboembolic disorders or bleeding disorders.

- Abnormal placenta location.
- Severe pregnancy complications such as severe pre-eclampsia.

- Malpresentations, contracted pelvis, multiple pregnancies, macrosomia, polyhydromnios.

- Previous cesarean delivery.

- Multiple Pregnancy.

Excluding previous caesarean delivery and multiple pregnancy is an attempt to bring a uniform platform for assessing the blood loss in absence of scarred uterus and already predisposed risk for atonic uterus as with multiple pregnancy which can be potential cause to PPH.

\section{Blood loss quantity calculation}

Blood was collected via suction container, soaked gauzes pads and operation table sheets were weighted. Blood measurements were obtained during the period from placental delivery to 2-hour post-partum. We ignored estimates of amniotic fluid and bleeding that occurred prior to placental delivery. The quantity of blood = (weight of used materials- weight of materials prior to surgery), plus the volume included in the suction container after placental delivery.

\section{Statistical analysis}

The collected data were numerically coded and entered in Microsoft excel 2007 and then transferred to Windows Statistical Package of Social Sciences (SPSS) software (version 21). Quantitative data were described as means and standard deviations and qualitative data were described as median and interquartile range. Normality of the data were checked using the Kolmogorov-Smirnov test. Demographic profile of patients in both the treatment groups was compared at baseline using chisquare or t test. Amount of blood loss in the two study groups was compared using the paired $t$ test for normal continuous data or Wilcoxon signed rank test for not normal continuous data. Categorical data was compared using the $\chi^{2}$ test. A two-sided p-value less than 0.05 was considered statistically significant. Statistic analysis has been evaluated by reputed statician assigned to our institutional NBE department.

\section{Observations and Results}

In the present study, 90 patients were included. Mean age of the study group was $30.44 \pm 3.39$ and of control group was $28.4 \pm 2.42$ years. 
Obstetric history of the patients included in the study revealed that $92.2 \%$ were primipara. Gestational age of the women included the study and control group ranged between 39 to 40 weeks.

\begin{tabular}{|c|c|c|c|}
\hline Group & $\begin{array}{l}\text { Age (Years) } \\
\text { (Mean } \pm \text { SD) }\end{array}$ & $\begin{array}{l}\text { Gestational } \\
\text { Age (Wks) } \\
\text { (Mean } \pm \text { SD) }\end{array}$ & $\begin{array}{c}\text { Gravidity } \\
\text { (Percentage) }\end{array}$ \\
\hline Study $(n=45)$ & $30.44 \pm 3.39$ & $38.67 \pm 1.11$ & 84.40 (primi) \\
\hline $\begin{array}{l}\text { Control } \\
(n=45)\end{array}$ & $28.40 \pm 2.42$ & $38.67 \pm 1.02$ & 15.60 (multi) \\
\hline
\end{tabular}

Table 1: Demographic distribution.

\begin{tabular}{|c|c|c|c|c|c|}
\hline \multirow{3}{*}{$\begin{array}{c}\text { Hemoglobin } \\
\text { (gm\%) }\end{array}$} & \multicolumn{4}{|c|}{ Group } & \multirow[b]{3}{*}{ p value } \\
\hline & \multicolumn{2}{|c|}{ Study $(n=45)$} & \multicolumn{2}{|c|}{ Control $(n=45)$} & \\
\hline & Mean & SD & Mean & SD & \\
\hline Before delivery & 11.65 & 0.75 & 11.51 & 0.74 & 0.37 \\
\hline After delivery & 10.93 & 0.74 & 10.79 & 0.74 & 0.39 \\
\hline Percent change & \multicolumn{2}{|c|}{$-6.18 \%$} & \multicolumn{2}{|c|}{$-6.26 \%$} & \\
\hline p value $* *$ & \multicolumn{2}{|c|}{$<0.001$} & \multicolumn{2}{|c|}{$<0.001$} & \\
\hline
\end{tabular}

Table 2: Hemoglobin status.

*Compares study and controls (student's t test);

** Compares pre and post-operative hemoglobin values within the same group (paired t test).

At baseline, before LSCS, hemoglobin was noted for all women. Mean hemoglobin was $11.65 \pm 0.75$ gm\% in the study group and $11.51 \pm 0.74 \mathrm{gm} \%$ in the control group.

After LSCS, mean hemoglobin levels when compared between the two group was found to be similar statistically ( $p$ value $=0.39$ ).

Mean volume of total blood loss amongst study group was $267.27 \pm 115.77 \mathrm{ml}$, while it was $428.13 \pm 98.24 \mathrm{ml}$ in the control group. The difference between the mean total blood loss amongst the study and control group was statistically significant ( $\mathrm{p}$ value < 0.001).

Mean surgical time was found to be $39.01 \pm 5.17$ minutes across the study group and $39.09 \pm 5.48$ minutes amongst the control group and the difference was not statistically significant.

\begin{tabular}{|c|c|c|c|c|c|}
\hline \multirow{3}{*}{$\begin{array}{l}\text { Gauze mop } \\
\text { weight (gm) }\end{array}$} & \multicolumn{4}{|c|}{ Group } & \multirow[b]{3}{*}{$\begin{array}{c}\text { p } \\
\text { value* }^{*}\end{array}$} \\
\hline & \multicolumn{2}{|c|}{ Study } & \multicolumn{2}{|c|}{ Control } & \\
\hline & Mean & SD & Mean & SD & \\
\hline Before delivery & 225.02 & 30.679 & 234.13 & 19.92 & 0.09 \\
\hline After delivery & 348.62 & 94.47 & 390.82 & 56.90 & $<0.05$ \\
\hline $\begin{array}{l}\text { Percentage } \\
\text { change }\end{array}$ & \multicolumn{2}{|c|}{+54.93} & \multicolumn{2}{|c|}{+66.92} & \\
\hline \multirow[t]{2}{*}{$\mathrm{p}$ value } & \multicolumn{2}{|c|}{0.89} & \multicolumn{2}{|c|}{$<0.01$} & \\
\hline & \multicolumn{4}{|c|}{ Group } & \\
\hline \multirow{2}{*}{$\begin{array}{l}\text { Blood volume } \\
\text { (in ml) }\end{array}$} & \multicolumn{2}{|c|}{ Study } & \multicolumn{2}{|c|}{ Control } & \\
\hline & Mean & SD & Mean & SD & $\begin{array}{c}\text { p } \\
\text { value* }^{*}\end{array}$ \\
\hline Floor spill & 0 & 0 & 0 & 0 & NA \\
\hline Blood in suction & 113.56 & 81.44 & 255.56 & 89.96 & $<0.001$ \\
\hline $\begin{array}{l}\text { Blood obtained } \\
\text { from vaginal } \\
\text { toileting }\end{array}$ & 14.76 & 4.27 & 15.89 & 5.46 & 0.28 \\
\hline Total blood loss & 267.27 & 115.77 & 428.13 & 98.24 & $<0.001$ \\
\hline
\end{tabular}

Table 3: Comparison of volume of blood loss.

\section{Discussion}

During placental delivery, fibrinogen and fibrin are rapidly degraded, whereas plasminogen activators and fibrin degradation products (FDP) increase due to activation of the fibrinolytic system. This activation can last up to 6-10 hours postpartum, causing more bleeding. It was because of this activation of the fibrinolytic system that we decided to use TXA in this trial. In the present study, we observed a significant fall in mean hemoglobin levels in both study and control group. However, this fall in mean hemoglobin was found to be similar ( $p$ value $=0.39$ ) in both the group. Mean of total blood loss among study group was $267.27 \pm 115.77 \mathrm{ml}$, while it was $428.13 \pm 98.24 \mathrm{ml}$ in the control group. The difference between the mean total blood loss was statistically significant ( $p$ value $<0.001$ ) between the two groups.

Estimation of blood loss during caesarean section is subjective, and it is difficult to make a true estimate because the bleeding volume is affected when mixed with amniotic fluid. Due to this reason, hemoglobin and hematocrit values are able to present more objective results. We also obtained volumes of blood lost in floor spill, 
volume of blood in suction and blood volume from vaginal toileting in addition to increase in weight of mops used.

Similar to our findings, Khing., et al. found that the mean total blood loss was significantly lower at $388.0 \pm 22.8 \mathrm{ml}$ in the Tranexamic acid group as compared to that of $432.4 \pm 30.8 \mathrm{ml}$ in the control group (p value $<0.001$ ) [6]. Shahid and Khan also reported that the drop of hemoglobin was significantly more in the placebo group $(\mathrm{p}<0.001)$ as compared with the Tranexamic acid group [7].

Senturk., et al. found there was a significant difference $(\mathrm{p}=$ $0,034)$ when hemoglobin loss of two groups was compared. More hemoglobin loss was observed in control group compared with the study group [8].

Ahmed., et al. reported significantly higher mean hemoglobin levels in the Tranexamic acid group (10.3 g/dl) post operatively (i.e. significantly less fall in hemoglobin levels) as compared to that in the control group $(9.2 \mathrm{~g} / \mathrm{dl})[9]$.

Ahmed., et al. also demonstrated lower total amount of blood loss in Tranexamic acid group (391 ml) when compared to the control group (597 ml) [9].

Abdel-Aleem., et al. also reported a significantly higher drop in hemoglobin levels in the control group as compared to those in the study group [10]. In addition in their study, Abdel-Aleem., et al. measured blood loss from the start of skin incision and up to two hours postpartum. They found that there was statistically significant reduction in the mean blood loss among the study group $(241.61 \pm$ SE6.77 $\mathrm{ml})$ who received Tranexamic acid in comparison to the control group $(510.66 \pm \mathrm{SE} 7.72 \mathrm{ml})$.

Lakshmi and Abraham reported significant reduction in blood loss calculated from placental delivery till end of surgery viz $347.17 \mathrm{ml}$ in study group versus $517.72 \mathrm{ml}$ in control group $(\mathrm{p}<$ 0.001 ) [11].

We observed the mean surgical time to be $39.01 \pm 5.17$ minutes among the study group and $39.09 \pm 5.48$ minutes among controls. The difference between the mean surgical time was not statistically significant. On the contrary, Khing., et al. reported that the duration of CS was significantly reduced among Tranexamic acid cases $(42.00 \pm 5.00$ minutes) as compared to that of control cases (47.40 \pm 3.90 minutes) $(\mathrm{p}<0.001)$. There were no thromboembolic events present in the study Gastrointestinal problems and hypersensitivity are other common side effects of Tranexamic acid but none were observed in our study.

\section{Limitations}

There were a few limitations of this study.

We used oxytocin in our study as part of routine protocol. The application of any medication that has a bleeding reduction effect can reduce the accuracy of the study. But we used oxytocin in all patients in same dose, both in study and control group and thus the add on (or confounding) effect of oxytocin would reduce. Next, we could not assess and report effect of Tranexamic acid on neonates.

\section{Conclusion}

The findings of the present study confirm the efficacy of Tranexamic acid in reducing bleeding in cesarean section. This matter is particularly important for reducing the rate of maternal mortality and morbidity in countries like India where antenatal anemia is a public health concern and considering the high costs and risks associated with blood transfusion, this drug should be used more commonly by obstetricians.

\section{Bibliography}

1. Betran AP., et al. "Rates of caesarean section: analysis of global, regional and national estimates". Paediatric and Perinatal Epidemiology 21.2 (2007): 98-113.

2. Lauer JA., et al. "Determinants of caesarean section rates in developed countries: supply, demand and opportunities for control". World Health Report (2010).

3. International Institute for Population Sciences (IIPS) and Ministry of Health and Family Welfare. National Family Health Survey-4 (NFHS-4), India-Factsheet.

4. World Health Organization. The World Health Report, 2005: Make Every Mother and Child Count. World Health Organization: Geneva (2005).

5. Thorsen S. "Differences in the binding to fibrin of native plasminogen modified by proteolytic degradation: influence of w- aminocaproic acids". Biochimica et Biophysica Acta 393 (1975): 55-65. 
6. Khing R., et al. "Effect of Intravenous Administration of Tranexamic Acid in Reducing Blood Loss During and After Caesarean Section". JMSCR 4.7 (2016): 11297-11303.

7. Shahid A and Khan A. "Tranexamic acid in decreasing blood loss during and after caesarean section". Journal of College of Physicians and Surgeons Pakistan 23 (2013): 459-462.

8. Senturk MB., et al. "Tranexamic acid for cesarean section: a double blind, placebo controlled, randomized clinical trial". Archives of Gynecology and Obstetrics 287 (2013): 641-645.

9. Ahmed MR., et al. "Efficacy of tranexamic acid in decreasing blood loss in elective caesarean delivery". Journal of MaternalFetal and Neonatal Medicine 28 (2015): 1014-1048.

10. Abdel-Aleem H., et al. "Effectiveness of Tranexamic acid on blood loss in patients undergoing elective cesarean section: randomized clinical trial". Journal of Maternal-Fetal and Neonatal Medicine 26 (2013): 1705-1709.

11. Lakshmi SJD and Abraham R. "Role of Prophylactic TXA in Reducing Blood Loss During Elective Cesarean Section". Journal of Clinical and Diagnostic Research 10.12 (2016): QC17-QC21.

12. WOMAN Trial Collaborators. "Effect of early tranexamic acid administration on mortality, hysterectomy, and other morbidities in women with post-partum haemorrhage (WOMAN): an international, randomised, double-blind, placebo-controlled trial". Lancet 389 (2017): 2105-2116.

\section{Volume 3 Issue 8 August 2021}

(C) All rights are reserved by Anita Kant, et al. 